\title{
Rheumatoid synovial endothelial cells secrete decreased levels of tissue inhibitor of MMP (TIMP1)
}

\author{
Christopher J Jackson, Jacky Arkell, Minh Nguyen
}

\begin{abstract}
Objectives-Angiogenesis (the formation of new blood vessels) is a major component of the inflammatory pannus in rheumatoid arthritis (RA). Matrix metalloproteinase (MMP) secretion by microvascular endothelial cells is an essential step in angiogenesis. The secretion of MMP1, MMP2, MMP9, and TIMP1 by human microvascular endothelial cells derived from RA synovium (RASE) to normal synovium (NSE) and neonatal foreskin (FSE) was compared.

Methods-Confluent monolayers of endothelial cells in basal medium were preincubated for 24 hours in the presence or absence of phorbol myristate acetate (PMA, 100 ng/ml). MMP1 activity was measured using a spectrophotometric assay and western blotting. MMP2 and MMP9 were measured using zymography. TIMP1 was measured by enzyme linked immunosorbent assay and western blotting.
\end{abstract}

Results-There was little difference between the amounts of MMP2 secreted by any of the cell lines. In response to PMA both synovial cell types showed a significantly higher MMP1 and MMP9 activity compared with FSE, although there was no difference between RASE and NSE. Tumour necrosis factor $\alpha$ had minimal effect on MMP activity. There was a striking decrease in the amount of TIMP1 secreted by RASE compared with normal synovium.

Conclusions-As overall MMP activity is a balance between the amount of MMP and TIMP1 present, the low levels of TIMP1 produced by RASE would shift the balance in favour of increased MMP activity by these cells. This is likely to contribute to the angiogenic potential of RASE. (Ann Rheum Dis 1998;57:158-161)

Correspondence to: Dr C Jackson, Sutton Arthritis Research Laboratory, Department of Rheumatology, University of Sydney at Royal North Shore Hospital, St Leonards NSW, 2065, Australia.

Accepted for publication 23 January 1998 sels) is a major component of the inflammatory pannus in rheumatoid arthritis (RA). ${ }^{12}$ The initial stage of angiogenesis requires the secretion of matrix metalloproteinases (MMPs) by endothelial cells. ${ }^{3}$ The MMPs are a group of matrix degrading enzymes that can degrade all the components of the extracellular matrix. MMP1 (type I collagenase) is one of four known collagenases, capable of degrading fibrillar collagens. The gelatinases (MMP2 and MMP9) degrade basement membrane collagens, gelatins, and elastin. The regulation of MMP activity is complex and tightly controlled. The specific tissue inhibitors of metalloproteinases (TIMPs) provide fine control by binding in a 1:1 complex with MMPs and inhibiting their action.

The vasculature is lined by a heterogenous population of endothelial cells. Not only are there differences between endothelium derived from different microvascular endothelial beds, but there are also differences in endothelial cells from the same bed in different disease states. For example, RA synovial endothelial cells express higher levels of adhesion molecules than normal synovial endothelium. ${ }^{4}$ To study synovial angiogenesis it is important to use synovial endothelial cells. In this study we examined the secretion of MMP1, MMP2, MMP9, and TIMP1 by human microvascular endothelial cells derived from RA synovium (RASE), normal synovium (NSE), and neonatal foreskin (FSE).

\section{Methods}

CELLS

Human microvascular endothelial cells were isolated from RASE, NSE, and FSE using Ulex Europaeus 1 coated dynabeads as described previously. ${ }^{5}$ RASE was obtained from three patients undergoing knee joint replacement. All patients met the American College of Rheumatology criteria, ${ }^{6}$ with at least four of seven criteria. NSE was obtained from the wrist joints of three patients undergoing carpal tunnel decompression who had no evidence of inflammatory disease. FSEs (three specimens) were obtained after circumcision. All cells were grown and maintained in Biorich medium containing 30\% normal pooled human serum (derived from 10 healthy volunteers) plus 100 $\mu \mathrm{g} / \mathrm{ml}$ endothelial cell growth supplement (ECGS, prepared as described by Maciag et $\mathrm{al}^{7}$ ) and $50 \mu \mathrm{g} / \mathrm{ml}$ heparin (Sigma Chemical Company, St Louis, USA). 

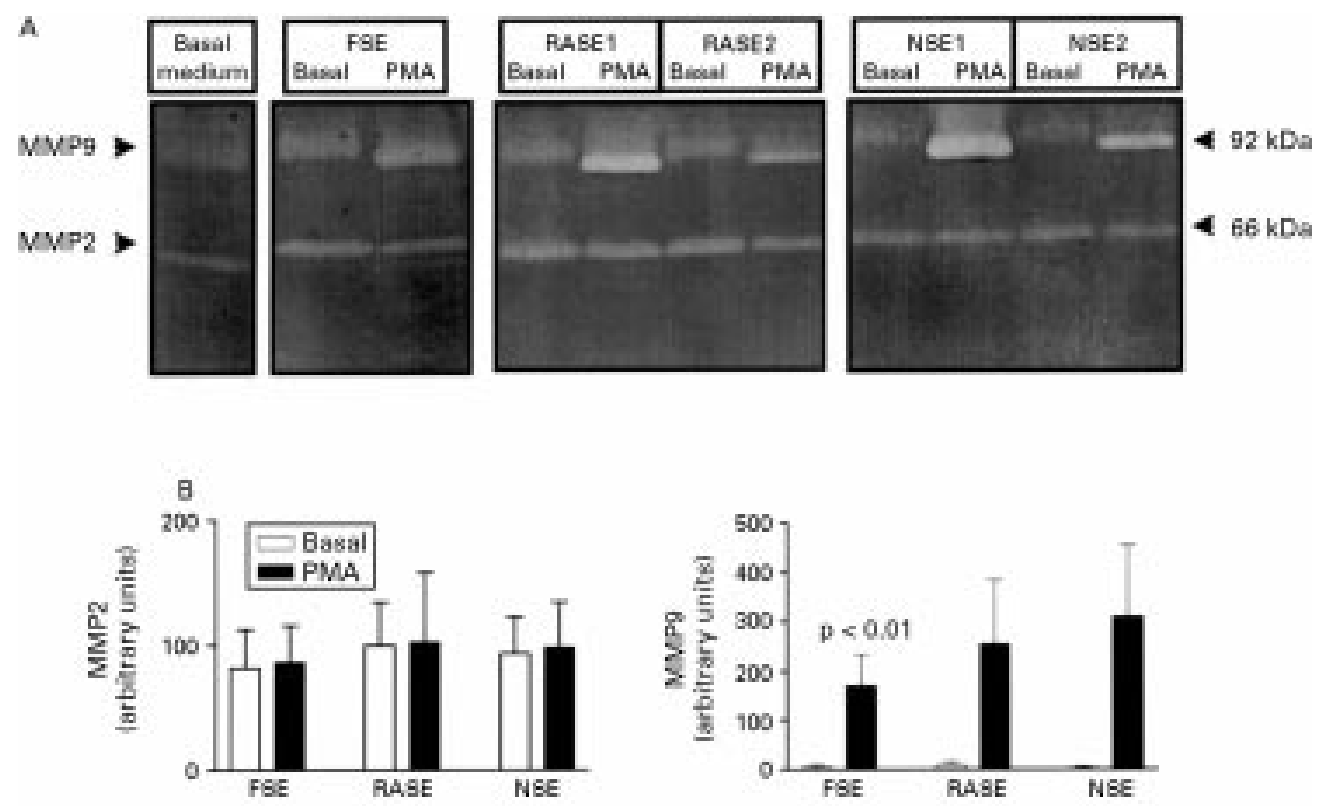

Figure 1 Gelatin substrate zymography was used to detect MMP2 and MMP9 in endothelial cell supernatants. (A) In the absence of cells, basal medium contained MMP9 and MMP2 activity. Endothelial cells derived from one neonatal foreskin cell line and two different RASE lines (RASE1, RASE2) and two different NSE lines (NSE1, NSE2) were incubated for 24 hours in basal medium containing $100 \mathrm{ng} / \mathrm{ml}$ PMA or no test agent (Basal). Supernatants were assayed for MMPs using zymography. (B) Scanning densitometry was performed on zymograms from three different cell lines each of FSE, RASE, and NSE. Results are expressed as the mean (SD) in arbitrary densitometry units for both MMP2 and MMP9. $p<0.01$ represents the statistical difference between neonatal foreskin and the two synovial cell types.

EXPERIMENTAL PROTOCOL

Confluent endothelial cells in 24 well plates (Nunc, Kamstrup, Denmark) were preincubated in basal medium (Biorich plus $1 \%$ normal pooled serum) for eight hours, then incubated with fresh basal medium in the presence of $100 \mathrm{ng} / \mathrm{ml}$ phorbol myristate acetate (PMA, Sigma), $100 \mathrm{ng} / \mathrm{ml}$ tumour necrosis factor $\alpha$ (TNF, a kind gift from Dr Deborah Rathjen, Peptech Limited, North Ryde, Australia) or no test agent. After 24 hours the conditioned medium was removed and assayed for MMPs and TIMP1. To ensure that the results were standardised between wells, the protein content of the cell sheet was measured using the Bradford assay (Bio-Rad Laboratories, Hercules, California, USA). The level of protein did not differ between any of the cell sheets used in the experiments (data not shown).

MMP AND TIMP1 ASSAYS

MMP1 activity was measured using the spectrophotometric assay of Nethery et $\mathrm{al}^{8}$ and western blotting. MMP2 and MMP9 were measured by zymography, using $10 \%$ SDSPAGE copolymerised with $1 \mathrm{mg} / \mathrm{ml}$ gelatin as previously described. ${ }^{9}$ Zymograms were semiquantitated using scanning densitometry (Molecular Analyst software, Bio-Rad) and the results were expressed as densitometry units, after subtracting the level of MMP activity in the basal medium. TIMP1 was measured by western blotting and ELISA (Amersham). Antibodies to MMP1 and TIMP1 (Oncogene Science) were used at $1 \mu \mathrm{g} / \mathrm{ml}$ for western blotting. Statistical analysis was performed using one way analysis of variance followed by the Student-Newman-Keuls test.

\section{Results}

MMP2 AND MMP9 SECRETION

Under basal conditions, there was no MMP9 detected in the supernatant of any cell lines tested (fig 1). PMA induced the secretion of MMP9 by all endothelial cell lines. Scanning densitometry revealed that there was no difference between NSE and RASE, however both synovial cell types secreted more MMP9 than FSE $(\mathrm{p}<0.01)$ (fig $1(\mathrm{~B})$ ). There was no difference between the total amount of MMP2 secreted by any of the cell lines.

\section{MMP1 SECRETION}

Using the spectrophotometric assay, low levels of MMP1 were detected in all endothelial cell lines under basal conditions (data not shown), although this was not always detectable using the less sensitive western blotting technique (fig 2). In response to PMA, all cell lines increased the secretion of MMP1. Both synovial cell types showed a significantly higher increase in MMP1 activity over basal medium compared with FSE (fig 3). There was no difference between RASE and NSE. TNF had minimal effect on MMP1 activity.

TIMP1 SECRETION

There was a striking difference between NSE and RASE in their secretion of TIMP1. Under basal conditions, TIMP1 secretion by RASE was barely detectable, while NSE secreted substantial quantities of TIMP1, as detected by western blotting (fig 2). In response to PMA all cell lines increased their secretion of TIMP1, however, again there was a dramatic difference between NSE and RASE. All three cell lines of RASE secreted markedly lower levels of TIMP1 than NSE (fig 2). We performed 


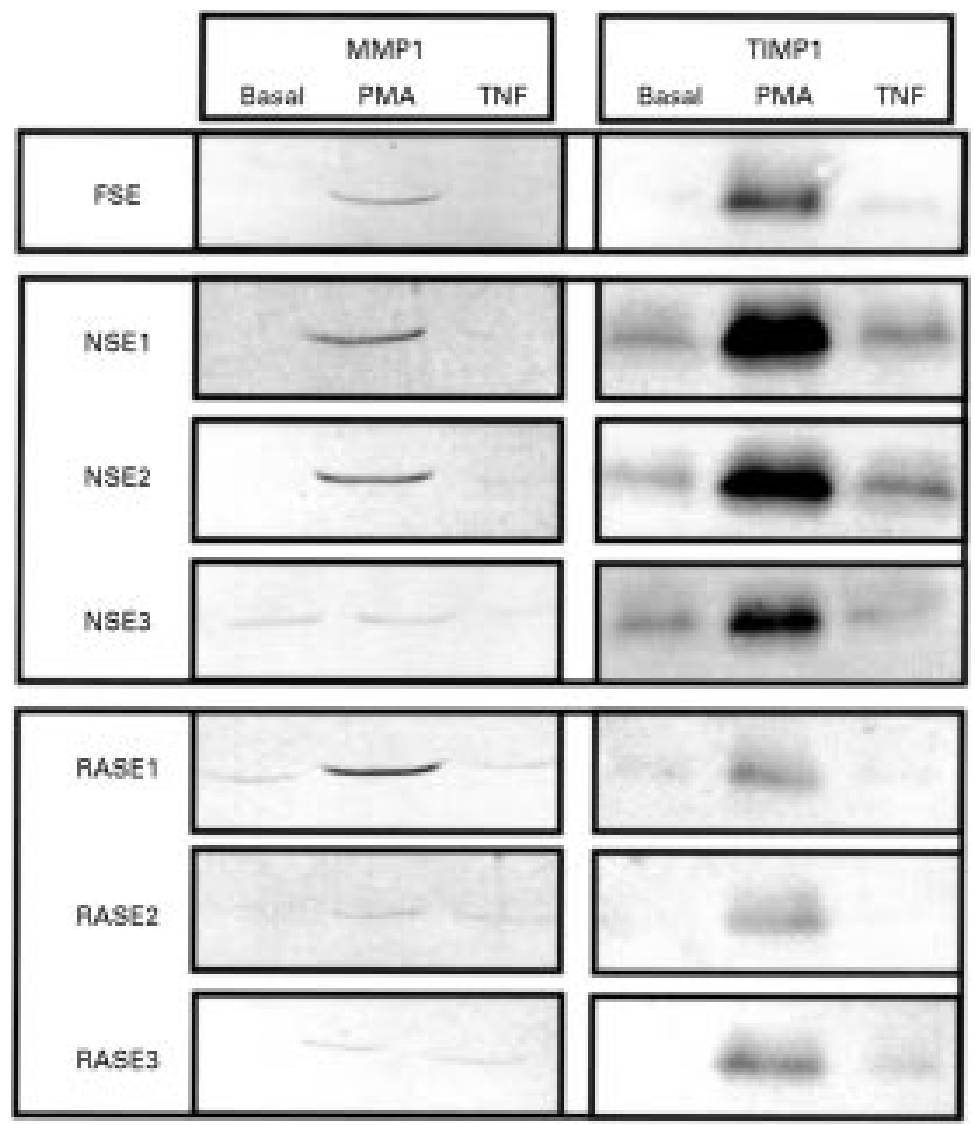

Figure 2 MMP1 and TIMP1 secretion by endothelial cells was assessed by western blotting. Confluent endothelial cells were pre-incubated in basal medium for eight hours then stimulated with $100 \mathrm{ng} / \mathrm{ml} P M A, 100 \mathrm{ng} / \mathrm{ml} T \mathrm{TNF}$ or no test agent (Basal) for 24 hours. The supernatants collected and assayed for MMP activity using specific antisera against MMP1 or TIMP1. Results are shown for one FSE cell line and three cell lines each of NSE and RASE.

ELISA on two cell lines each of NSE and RASE. In response to PMA, NSE (490 (112) $\mathrm{ng} / \mathrm{ml}$, mean (SEM)) secreted significantly higher levels of TIMP1 than did RASE (101 (9) $\mathrm{ng} / \mathrm{ml}, \mathrm{p}<0.01)$. TNF had little effect on TIMP1 secretion by any cell line (fig 2).

\section{Discussion}

The striking finding of this study was that RASE secrete markedly lower levels of TIMP1 compared with NSE. This was observed in the absence of any stimulus as well as in response to PMA. The reason for the low levels of TIMP1 secretion by RASE is unclear. We have recently shown that there are differences in TIMP1 secretion between macrovascular and microvascular endothelial cells. ${ }^{11}$ However, it is unlikely that the vessel size accounts for the differences observed in the current study between RASE and NSE, because both cell types are derived from similar tissue using the same isolation procedure. It is possible that reduced TIMP1 secretion by RASE is part of the acquired functional abnormalities of these cells. RASE undergo excessive proliferation or damage, or both, in vivo, ${ }^{12}$ which may be sustained in vitro. Alternatively, an autocrine mechanism may be operating in RASE whereby the resulting low levels of TIMP1 secretion are maintained in vitro. Another pos-

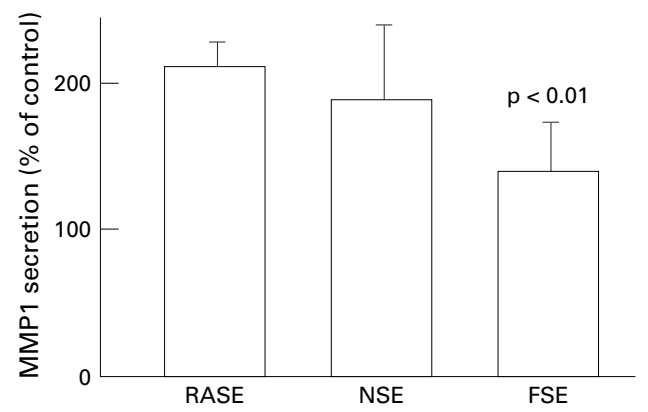

Figure 3 MMP1 secretion by endothelial cells was measured using a spectrophotometric assay. Endothelial cells were stimulated with $100 \mathrm{ng} / \mathrm{ml} P M A$ for 24 hours and the supernatant assayed for MMP1 activity. Results were pooled from three different experiments using FSE ( $n=3)$, RASE ( $n=3)$, and NSE $(n=2)$ and expressed as MMP1 secretion, as a percentage of the basal control (mean (SD)).

sibility is that there is an inherent abnormality in the ability of RASE to produce TIMP1. The exact mechanism controlling the decreased TIMP1 secretion by RASE needs to be further investigated.

The secretion of MMP1 and MMP9 by both synovial cell types was higher than FSE. However, we found no difference in the secretion of these enzymes between RASE and NSE. As the overall proteolytic activity is determined by the balance between the amounts of MMPs and their inhibitors, the low TIMP1 and normal MMP levels by RASE would allow for excessive matrix degradation by these cells.

It has been suggested that excessive MMP activity is a major causative factor for joint destruction in RA. ${ }^{13}{ }^{14}$ This paper is the first to report increased MMP activity by RASE. It is unknown whether endothelial derived MMP activity contributes directly towards cartilage degradation. The joint houses many cell types, such as neutrophils, macrophages, and synoviocytes that are capable of secreting proteases. ${ }^{15}$ It is more likely that the increased MMP activity by RASE indirectly contributes towards joint destruction by promoting angiogenesis. Normal articular cartilage is avascular and resistant to invasion by new vessel growth. In RA, this barrier is broken and blood vessels grow into the articular cartilage, contributing to its destruction. The new blood vessels also provide a vehicle to allow inflammatory cells to enter the joint cavity. ${ }^{2}$ Our finding that TIMP secretion is decreased in RASE provides evidence of a possible mechanism of increased angiogenic activity of these cells.

We wish to thank Kate Gibbons, Associate Professor Leslie Schrieber, and Dr Ross Davey for their helpful discussions. We are grateful to the Northern Sydney Area Health Service, Arthritis Foundation of Australia, Rebecca L Cooper Foundation, Henry Langley Fellowship, and the Wenkart Foundation for their financial support.

1 Folkman J. Angiogenesis in cancer, vascular, rheumatoid and other disease. Nature Medicine 1995;1:27-31.

2 Klagsbrun M, Folkman J. Angiogenesis. In: Sporn MB, Roberts AB, eds. Handbook of experimental pharmacology. Berlin: Springer-Verlag, 1990:549-86.

3 Rifkin DB, Gross JL, Moscatelli D, Jaffe E. Proteases and angiogenesis: production of plasminogen activator and collagenase by endothelial cells. In: Nossel H, L., Vogel HJ, eds. Pathobiology of the endothelial cell. New York: Academic eds. Pathobiology of the
Press, 1982:191-228. 
4 To SST, Newman PM, Hyland VJ, Robinson BG, Schrieber L. Regulation of adhesion molecule expression by human synovial microvascular endothelial cells in vitro. Arthritis Rheum 1996;39:467-77.

5 Jackson CJ, Garbett PK, Nissen B, Schrieber L. Binding of human endothelium to Ulex Europaeus I-coated dynabeads: application to the isolation of microvascular dynabeads: application to the isolation
endothelium. J Cell Sci 1990;96:257-62.

6 Arnett FC, Edworthy SM, Bloch DA, McShane DJ, Fries JF, Cooper NS, et al. The American Rheumatism Association 1987 revised criteria for the classification of rheumatoid arthritis. Arthritis Rheum 1988;31:315-24.

7 Maciag T, Cerundolo J, Ilsley S, Kelley PR, Forand R. An endothelial cell growth factor from bovine hypothalamus: Identification and partial characterization. Proc Natl Acad Sci USA 1979;76:5674-78.

8 Nethery A, Lyons JG, O'Grady RL. A spectrophotometric collagenase assay. Anal Biochem 1986;159:390-5.

9 Herron GS, Werb Z, Dwyer K, Banda MJ. Secretion of metalloproteinases by stimulated capillary endothelial cells. I. Production of procollagenase and prostromelysin exceeds expression of proteolytic activity. J Biol Chem 1986;261: $2810-13$
10 Hanemaaijer R, Koolwijk P, Leclercq L, Devree WJA, Vanhinsbergh VWM. Regulation of matrix metalloproteinase hinsbergh VWM. Regulation of matrix metalloproteinase
expression in human vein and microvascular endothelial expression in human vein and microvascular endothelial
cells - effects of tumour necrosis factor-alpha, interleukin-1 and phorbol ester. Biochem J 1993;296:803-9.

11 Jackson CJ, Nguyen M. Human microvascular differ from macrovascular endothelial cells in their expression of matrix metalloproteinases (MMPs). Int J Biochem Cell Biol 1997;29:1167-77

12 Wilder RL, Case JP, Crofford LJ, Kumkumian GK, Lafytis R, Remmers EF, et al. Endothelial cells and the pathogenesis of rheumatoid arthritis in humans and streptococcal cell wall arthritis in lewis rats. J Cell Biochem 1991;45:162-6.

13 Brinckerhoff CE. Joint destruction in arthritis: metalloproteinases in the spotlight. Arthritis Rheum 1991;34: 1073-5.

14 Martel-Pelletier J, McCollum R, Fujimoto N, Obata K, Cloutier J, Pelletier J. Excess of metalloproteases over tissue inhibitor of metalloprotease may contribute to cartilage degradation in osteoarthritis and rheumatoid arthritis. Lab Invest 1994;70:807-15.

15 Gravallese EM, Darling JM, Ladd AL, Katz JN, Glimcher LH. Insitu hybridization studies of stromelysin and collagenase messenger RNA expression in rheumatoid synovium. Arthritis Rheum 1991;34:1076-84. 